\title{
Initial Experience with Mirabegron for the Treatment of Neurogenic Lower Urinary Tract Dysfunction
}

\author{
Heyi Zhen', Tianhai Huang², Xiaoyi Yang², Qiuling Liu², Qingqing Li², Maping Huang2*, Hui Chen²* \\ ${ }^{1}$ Department of Traumatic Brain Injury Rehabilitation, Guangdong Province Work Injury Rehabilitation Hospital, Guangzhou, \\ China \\ ${ }^{2}$ Department of Urology, Guangdong Provincial Work Injury Rehabilitation Hospital, Guangzhou, China \\ Email: ^149713097@qq.com, ^doc.chenhui @163.com
}

How to cite this paper: Zhen, H.Y., Huang, T.H., Yang, X.Y., Liu, Q.L., Li, Q.Q., Huang, M.P. and Chen, H. (2021) Initial Experience with Mirabegron for the Treatment of Neurogenic Lower Urinary Tract Dysfunction. Open Journal of Urology, 11, 305-311. https://doi.org/10.4236/oju.2021.118028

Received: July 3, 2021

Accepted: August 15, 2021

Published: August 18, 2021

Copyright $\odot 2021$ by author(s) and Scientific Research Publishing Inc. This work is licensed under the Creative Commons Attribution International License (CC BY 4.0).

http://creativecommons.org/licenses/by/4.0/ (c) (i) Open Access

\begin{abstract}
Background: Though anticholinergic drugs are considered the standard treatment for neurogenic detrusor overactivity, it is far from an ideal tool, because of their adverse effects such as Constipation or not respond sufficiently for a substantial proportion of patients. Recently mirabegron has become a commonly used overactive bladder medication in the general population, but few studies about mirabegron for the treatment of neurogenic detrusor overactivity. Objective: To evaluate the efficacy and safety of mirabegron for the treatment of neurogenic lower urinary tract dysfunction. Study Design: Prospective study. Methods: This prospective study included 13 adult patients with neurogenic lower urinary tract dysfunction as a result of spinal cord injury. All patients receiving mirabegron treatment $(50 \mathrm{mg}$ once daily) at least 6 weeks. The effective outcomes included the mean urine volume per catheterization, urinary incontinence episodes and Incontinence Specific Quality of Life Instrument. We monitored the blood pressure and heart rate to assess the cardiovascular safety, other adverse events were also recorded. Results: A total of 13 patients were included. After 6 weeks of treatment, all patients experienced a significant increase in the mean volume of per catheterization from $238.46 \pm 65.43 \mathrm{ml}$ to $327.69 \pm 59.04 \mathrm{ml}(\mathrm{p}=0.001)$. There is a significant reduction in the volume of urine leakage $(463.85 \pm 247.98 \mathrm{ml}$ VS $180.00 \pm$ $190.96 \mathrm{ml}, \mathrm{p}=0.003)$ and incontinence episodes per $24 \mathrm{~h}(4.46 \pm 2.03 \mathrm{VS} 1.92$ $\pm 1.50, \mathrm{p}=0.001)$. Significant improvement in mean Incontinence Specific Quality of Life Instrument was also found $(\mathrm{p}=0.001)$. No patients reported dry mouth during the study, and the cardiovascular safety were acceptable. Conclusion: Mirabegron is safe and effective in the treatment of neurogenic lower urinary tract dysfunction. It might be a good choice for reducing the cessation of clean intermittent catheterization.
\end{abstract}




\section{Keywords}

Neurogenic Lower Urinary Tract, Mirabegron, Detrusor Overactivity, Spinal Cord Injury

\section{Introduction}

Detrusor overactivity (DO) is characterized by spontaneous or provoked involuntary detrusor contractions during storage phase in urodynamic investigation [1] [2]. Neurogenic DO (NDO) is DO caused by various neurogenic diseases such as brain tumors, dementia, multiple sclerosis, Parkinson's disease, stroke and spinal cord injury (SCI) [3]. NDO can cause a variety of long-term complications such as urinary incontinence (UI), stones, hydronephrosis, recurrent urinary tract infection and Vesicoureteral reflux (VUR); the most dangerous being damage of renal function. These complications may markedly impact the quality of life of people with SCI, including limiting their behavior, causing social embarrassment and possibly threatening their life [4].

Anticholinergic drugs are considered the standard treatment for NDO. The positive effects of oxybutynin, trospium chloride, tolterodine, propiverine, and imidafenacin in increasing the bladder capacity and reducing the intravesical pressure have been documented in several studies [5]. Nevertheless, treatment with antimuscarinic drugs is frequently discontinued due to side effects (dry mouth and constipation) or a lack of efficacy [6]. In particular in patients with SCI, who suffer from a neurogenic bowel dysfunction, the concomitant antmiuscarinic treatment will worsen the constipation. Therefore, there is a need for therapy alternatives.

In recent years, mirabegron, a $\beta 3$-adrenoreceptor agonist, was developed to target sympathetic nerve stimulated relaxation of the bladder, a mechanism of action that improves the storage capacity of the bladder without inducing anticholinergic-associated adverse events [7] [8].

Clinical trials have demonstrated its efficacy and safety [9] [10] and observational studies suggest improved persistence and adherence when compared to antimuscarinics [11]. As such, it has become a commonly used overactive bladder medication in the general population [12]. But few studies were carried on the treatment of mirabegron for NDO. The aim of this study was evaluated to evaluate the efficacy and safety of mirabegron for the treatment of neurogenic lower urinary tract dysfunction (NLUTD).

\section{Material and Methods}

In this prospective observational study, a total of 13 patients who received treatment with mirabegron $50 \mathrm{mg}$ once daily at least 6 weeks from April to June 2021 in our SCI center were included. All eligible inpatients over 18 years of age with non-acute SCI (i.e. no progression in neurological symptoms in the previous 3 
months) were screened for enrollment. The main inclusion criteria were: 1) urodynamic presence of DO; 2) bothersome urinary symptoms (frequency, urgency, urgency incontinence) and at least one episode of urgency/unaware incontinence during the 3-day voiding diary; 3) Patients or their caregivers agreed to perform clean intermittent catheterization (CIC); 4) Patients with previous injection of onabotuliuntoxin were included, if the last injection was at least 12 month before mirabegron treatment.

Exclusion criteria were: 1) intravesical botulinum toxin use within the last year; 2) clinically significant stressUI; 3) specific potentially complicating conditions (such as pelvic radiation, bladder cancer, or painful bladder syndrome), and the use of certain other medications; 4) subjects with symptomatic urinary tract infections (asymptomatic bacteriuria was not considered an exclusion criterion); 5) patients with severe cardiovascular (CV) disease (untreated hypertension, defined as a systolic blood pressure $(\mathrm{SBP})>180 \mathrm{mmHg}$ or diastolic blood pressure $(\mathrm{DBP})>110 \mathrm{mmHg}$, or untreated arrhythmia); 6) significant renal or liver dysfunction. Before treatment, all patients underwent urodynamic examination according to the International Continence Society standard.

The bladder management was oral mirabegron $50 \mathrm{mg}$ once daily combined with CIC 4 - 6 times each day. The mean urine volume per catheterization, UI episodes and complete dryness were determined from 3 consecutive days of the patient's bladder diary. Complete dryness is defined as less than one incontinence episode per $24 \mathrm{~h}$. The severity of incontinence was determined using the $24 \mathrm{~h}$ pad-weight test (24 PWT). All patients were asked to complete the Incontinence-Specific Quality-of-Life Instrument (I-QoL). Patients were monitored for significant changes in their blood pressure (BP), heart rate (HR), and liver or renal function.

Student's paired samples t-test was used as appropriate to compare and I-QoL, of pre-treatment and post-treatment. The results are shown as mean values and standard deviation (SD). All statistical tests were 2-sided, and a p-value of 0.05 or less was considered statistically significant. Statistical analyses were performed with SPSS 13.0 software (SPSS Inc., Chicago, IL, USA).

\section{Results}

A total of 13 patients included in our study, the mean age was $41.62 \pm 11.98$ years, mean injury duration $0.86 \pm 0.61$ months (Table 1 ). The distribution of SCI levels was 6 (46\%) cervical, 6 (46\%) thoracic and 1 (8\%)Lumbar. The distribution of the American Spinal Injury Association Impairment Scale (AIS) scores were: 6 (46\%) Grade A, 1 (8\%) Grade B, 4 (31\%) Grade C and 2 (15\%) Grade D.

Table 2 shows that the significant improvement in the mean volume of per catheterization from $238.46 \pm 65.43 \mathrm{ml}$ to $327.69 \pm 59.04 \mathrm{ml}(\mathrm{p}=0.001)$. There is a significant reduction in the volume of urine leakage $(463.85 \pm 247.98 \mathrm{ml} \mathrm{VS}$ $180.00 \pm 190.96 \mathrm{ml}, \mathrm{p}=0.003)$ and UI episodes per $24 \mathrm{~h}(4.46 \pm 2.03 \mathrm{VS} 1.92 \pm$ 1.50). Significant in the I-QoL from 54.15 to $69.92(\mathrm{p}=0.000)$. 
Table 1. The characteristics of the evaluated patients.

\begin{tabular}{cc}
\hline Variables & $\mathrm{n}=13$ \\
\hline Age-years (mean \pm SD) & $41.62 \pm 11.98$ \\
Time since SCI (years) & $0.86 \pm 0.61$ \\
Gender-N (\%) Male/Femal & $11(85 \%) / 2(15 \%)$ \\
Level of injury-N (\%) Cervical/Thoracic/Lumbar & $6(46 \%) / 6(46 \%) / 1(8 \%)$ \\
AIS-N (\%) A/B/C/D & $6(46 \%) / 1(8 \%) / 4(31 \%) / 2(15 \%)$ \\
\hline
\end{tabular}

SD, standard deviation; SCI, spinal cord injury; AIS, American Spinal Injury Association Impairment Scale.

Table 2. The significant improvement in clinical parameter.

\begin{tabular}{cccc}
\hline & Pre-treatment & Post-treatment & p-value \\
\hline Vcic & $238.46 \pm 65.43$ & $327.69 \pm 59.04$ & 0.001 \\
UI episodes & $4.46 \pm 2.03$ & $1.92 \pm 1.50$ & 0.001 \\
UI volume & $463.85 \pm 247.98$ & $180.00 \pm 190.96$ & 0.003 \\
I-Qol & $54.15 \pm 6.61$ & $69.92 \pm 9.73$ & 0.000 \\
\hline
\end{tabular}

Vcic, urine volume per catheterization; UI, urinary incontinence; I-Qol, Incontinence Specific Quality of Life Instrument.

Change from baseline in BP and HR were showed in Table 3. Though the increase in the SBP (75.54 VS 79.08, $\mathrm{p}=0.152$ ) was slightly larger than DBP (116.31 VS 117.46, $\mathrm{p}=0.786$ ) and HR (77.69 VS 78.15, $\mathrm{p}=0.759$.$) , all of them$ were not significant differences from baseline.

Though there is a little increase in the $\mathrm{BP}$ and $\mathrm{HR}$, no one described headache, palpitation, dry mouth, constipation and other side effects.

\section{Discussion}

After SCI, most individuals develop NLUTD, which in the majority of cases requires assisted bladder emptying rather than volitional voiding. CIC is recommended for bladder management after SCI since it has the lowest complication rate [13] [14] [15]. However, transitions from CIC to other less optimal strategies, such as indwelling catheters (IDCs) are common [16] [17]. Darshan P. Patel et al. revealed that convenience (36\%), urinary leakage (20\%), and the number of urinary infections (19\%) were the most common reasons for CIC cessation [17]. So, improve the patient's QoL is also an important aim in the treatment of NLUTD [18].

In our study mirabegron treatment significantly reduce the number of patients suffering from incontinence and the number of absorptive pads used. Especially 3 patients developed complete dryness after mirabegron treatment, they are less likely to worry about the disturbance from UI, which affects their physical activities, social relationships and feelings. The improve the IQoL might be beneficial for patients persist in carry out CIC. 
Table 3. Change from baseline in blood pressure and heart rate.

\begin{tabular}{cccc}
\hline & Pre-treatment & Post-treatment & p-value \\
\hline SBP & $116.31 \pm 11.03$ & $117.46 \pm 10.40$ & 0.786 \\
DBP & $75.54 \pm 6.86$ & $79.08 \pm 5.22$ & 0.152 \\
HR & $77.69 \pm 3.97$ & $78.15 \pm 3.63$ & 0.759 \\
\hline
\end{tabular}

SBP, systolic blood pressure; DBP, diastolic blood pressure; HR, heart rate.

The $\beta 3$-adrenergic agonist mirabegron was introduced into the treatment of $\mathrm{iOAB}$ in 2012. Its safety and efficacy in the treatment of this condition have been confirmed in a large number of well-designed studies [12]. In this study we also found improvement in the mean volume of per catheterization.

In human bladder, $\beta 3$-adrenoceptors account for $97 \%$ of total $\beta$-adrenoceptor messenger RNA [19], and they are thought to be the main subtype mediating relaxation of detrusor smooth muscle during the storage phase [20]. However, $\beta 3$-adrenoceptors are also expressed in CV tissues, so the treatment with $\beta 3$ adrenoceptor agonists may have "off-target" effects on regulation of the heart and vasculature [21]. In our study, there is a little increase in SBP, DBP and HR, but none of them were significant differences from baseline, similar to the previous studies [22] [23]. And no patients reported dry mouth during the study, so regarding safety, we did not observe severe side effects.

There is no doubt some limitations in the present study. The small number of patients included and the lack of a control group for comparison. Furthermore, we had no use urodynamic to evaluated the efficacy of $50 \mathrm{mg}$ mirabegron for the treatment of NLUTD.

\section{Conclusion}

Mirabegron is safe and effective in the treatment of neurogenic lower urinary tract dysfunction. It might be a good choice for reducing the cessation of clean intermittent catheterization.

\section{Funding}

This study was supported by:

Medical Scientific Research Foundation of Guangdong Province, China (grant number A2021221).

Traditional Chinese Medicine of Guangdong Province, China (grant number 20212034).

\section{Conflicts of Interest}

The authors declare no conflicts of interest regarding the publication of this paper.

\section{References}

[1] Abrams, P., Cardozo, L., Fall, M., Griffiths, D., Rosier, P., Ulmsten, U., et al. (2002) 
The Standardisation of Terminology of Lower Urinary Tract Function: Report from the Standardisation Sub-Committee of the International Continence Society. Neurourology and Urodynamics, 21, 167-178. https://doi.org/10.1002/nau.10052

[2] Schäfer, W., Abrams, P., Liao, L., Mattiasson, A., Pesce, F., Spangberg, A., et al. (2002) Good Urodynamic Practices: Uroflowmetry, Filling Cystometry, and Pressure-flow Studies. Neurourology and Urodynamics, 21, 261-274. https://doi.org/10.1002/nau.10066

[3] Hagen, E.M., Eide, G.E., Rekand, T., Gilhus, N.E. and Gronning, M. (2010) Traumatic Spinal Cord Injury and Concomitant Brain Injury: A Cohort Study. Acta Neurologica Scandinavica. Supplementum, 190, 51-57. https://doi.org/10.1111/j.1600-0404.2010.01376.x

[4] Denys, P., Corcos, J., Everaert, K., Chartier-Kastler, E., Fowler, C., Kalsi, V., et al. (2006) Improving the Global Management of the Neurogenic Bladder Patient. Part I. The Complexity of Patients. Current Medical Research and Opinion, 22, 359-365. https://doi.org/10.1185/030079906X89702

[5] Sugiyama, H., Uemura, O., Mori, T., et al. (2017) Effect of Imidafenacin on the Urodynamic Parameters of Patients with Indwelling Bladder Catheters Due to Spinal Cord Injury. Spinal Cord, 55, 187-191. https://doi.org/10.1038/sc.2016.168

[6] Kessler, T.M., Bachmann, L.M., Minder, C., Lohrer, D., Umbehr, M., Schunemann, H.J., et al. (2011) Adverse Event Assessment of Antimuscarinics for Treating Overactive Bladder: A Network Meta-Analytic Approach. PLoS ONE, 6, e16718. https://doi.org/10.1371/journal.pone.0016718

[7] Yamaguchi, O. and Chapple, C.R. (2007) Beta3-Adrenoceptors in Urinary Bladder. Neurourology and Urodynamics, 26, 752-756. https://doi.org/10.1002/nau.20420

[8] Kumar, V., Templeman, L., Chapple, C.R. and Chess-Williams, R. (2003) Recent Developments in the Management of Detrusor Overactivity. Current Opinion in Urology, 13, 285-291. https://doi.org/10.1097/00042307-200307000-00004

[9] Nitti, V.W., Auerbach, S., Martin, N., Calhoun, A., Lee, M. and Herschorn, S. (2013) Results of a Randomized Phase III Trial of Mirabegron in Patients with Overactive Bladder. Journal of Urology, 189, 1388-1395.

https://doi.org/10.1016/j.juro.2012.10.017

[10] Khullar, V., Amarenco, G., Angulo, J.C., et al. (2013) Efficacy and Tolerability of Mirabegron, a $\beta$ (3)-adrenoceptor Agonist, in Patients with Overactive Bladder: Results from a Randomised European-Australian Phase 3 Trial. European Urology, 63, 283-295. https://doi.org/10.1016/j.eururo.2012.10.016

[11] Chapple, C.R., Nazir, J., Hakimi, Z., et al. (2017) Persistence and Adherence with Mirabegron versus Antimuscarinic Agents in Patients with Overactive Bladder: A Retrospective Observational Study in UK Clinical Practice. European Urology, 72, 389-399. https://doi.org/10.1016/j.eururo.2017.01.037

[12] Tadrous, M., Elterman, D., Khuu, W., Mamdani, M.M., Juurlink, D.N. and Gomes, T. (2017) Publicly Funded Overactive Bladder Drug Treatment Patterns in Ontario over 15 Years: An Ecologic Study. Canadian Urological Association Journal, 12, E142-E145. https://doi.org/10.5489/cuaj.4541

[13] Jaggi, A., Drake, M., Siddiqui, E. and Fatoye, F. (2018) A Comparison of the Treatment Recommendations for Neurogenic Lower Urinary Tract Dysfunction in the National Institute for Health and Care Excellence, European Association of Urology and International Consultations on Incontinence Guidelines. Neurourology and Urodynamics, 37, 2273-2280. https://doi.org/10.1002/nau.23581

[14] Drake, M.J., Apostolidis, A., Cocci, A., et al. (2016) Neurogenic Lower Urinary Tract 
Dysfunction: Clinical Management Recommendations of the Neurologic Incontinence Committee of the Fifth International Consultation on Incontinence 2013. Neurourology and Urodynamics, 35, 657-665. https://doi.org/10.1002/nau.23027

[15] Groen, J., Pannek, J., Castro Diaz, D., et al. (2016) Summary of European Association of Urology (EAU) Guidelines on Neuro-Urology. European Urology, 69, 324 333. https://doi.org/10.1016/j.eururo.2015.07.071

[16] Cameron, A.P., Wallner, L.P., Tate, D.G., Sarma, A.V., Rodriguez, G.M. and Clemens, J.Q. (2010) Bladder Management after Spinal Cord Injury in the United States 1972 to 2005. Journal of Urology, 184, 213-217. https://doi.org/10.1016/j.juro.2010.03.008

[17] Patel, D.P., Herrick, J.S., Stoffel, J.T., et al. (2020) Reasons for Cessation of Clean Intermittent Catheterization after Spinal Cord Injury: Results from the Neurogenic Bladder Research Group Spinal Cord Injury Registry. Neurourology and Urodynamics, 39, 211-219. https://doi.org/10.1002/nau.24172

[18] Stöhrer, M., Blok, B., Castro-Diaz, D., Chartier-Kastler, E., Del Popolo, G., Kramer, G., et al. (2009) EAU Guidelines on Neurogenic Lower Urinary Tract Dysfunction. European Urology, 56, 81-88. https://doi.org/10.1016/j.eururo.2009.04.028

[19] Yamaguchi, O. (2002) Beta3-Adrenoceptors in Human Detrusor Muscle. Urology, 59, 25-29. https://doi.org/10.1016/S0090-4295(01)01635-1

[20] Wuest, M., Eichhorn, B., Grimm, M.O., Wirth, M.P., Ravens, U. and Kaumann, A.J. (2009) Catecholamines Relax Detrusor through Beta 2-Adrenoceptors in Mouse and Beta 3-Adrenoceptors in Man. Journal of Pharmacology and Experimental Therapeutics, 328, 213-222. https://doi.org/10.1124/jpet.108.142562

[21] Ursino, M.G., Vasina, V., Raschi, E., Crema, F. and De Ponti, F. (2009) The beta3Adrenoceptor as a Therapeutic Target: Current Perspectives. Pharmacological Research, 59, 221-234. https://doi.org/10.1016/j.phrs.2009.01.002

[22] Rossanese, M., Novara, G., Challacombe, B., et al. (2015) Critical Analysis of Phase II and III Randomised Control Trials (RCTs) Evaluating Efficacy and Tolerability of a $\beta 3$-Adrenoceptor Agonist (Mirabegron) for Overactive Bladder (OAB). BJU International, 115, 32-40. https://doi.org/10.1111/bju.12730

[23] Chapple, C.R., Kaplan, S.A., Mitcheson, D., et al. (2014) Mirabegron 50 mg OnceDaily for the Treatment of Symptoms of Overactive Bladder: An Overview of Efficacy and Tolerability over 12 Weeks and 1 Year. International Journal of Urology, 21, 960-967. https://doi.org/10.1111/iju.12568 